Article

\title{
Small-Scale Bioreactor for Sterile Hydroponics and Hairy Roots: Metabolic Diversity and Salicylic Acid Exudation by Hairy Roots of Hyoscyamus niger
}

\author{
Zana Jamal Kareem ${ }^{1,2, \dagger}$, Ling Su ${ }^{1, \dagger}$, Anna Rathgeb ${ }^{1}$, Anke Sirrenberg ${ }^{1}$, Franz Hadacek ${ }^{1}$, \\ Ahmad Hama Ameen H. Rashid ${ }^{2}$ and Petr Karlovsky ${ }^{1, * \mathbb{D}}$ \\ 1 Molecular Phytopathology and Mycotoxin Research, University of Goettingen, 37077 Goettingen, Germany \\ 2 College of Agricultural Sciences, University of Sulaimani, 334 Sulaimani, Iraq \\ * Correspondence: pkarlov@gwdg.de; Tel.: +49-(0)551-39-12918 \\ + These authors contributed equally to this work.
}

Received: 1 July 2019; Accepted: 25 July 2019; Published: 28 July 2019

check for updates

\begin{abstract}
The volume and complexity of commercial bioreactors for sterile hydroponics and hairy roots are too large for comparative analysis of many cultures. Here a small-scale bioreactor fabricated from standard glass materials and suitable for both airlift and bubble aeration mode is described. The performance of the bioreactor was tested by growing oilseed rape (Brassica napus L.) and rose plants (Rosa canina L.) in sterile hydroponics and by cultivating hairy roots of henbane (Hyoscyamus niger L.) and sesame (Hyoscyamus niger L.). Plants grown in hydroponics for up to six weeks did not show chloroses or necroses. Hairy roots grew faster or comparably fast in bioreactors as compared to shaking flasks. Root exudates of roses and exudates of hairy roots of henbane were subjected to targeted and nontargeted analysis by HPLC coupled with optical and mass spectrometric detectors. The diversity and concentration of hairy root exudates were higher in bioreactors than in shaking flasks. The composition of hairy root exudates of three accessions of $H$. niger did not match the genetic relatedness among the accessions. Hairy roots of Hyoscyamus niger exuded salicylic acid in amounts varying among plant accessions and between bioreactors and shaking flask cultures.
\end{abstract}

Keywords: hairy roots; root exudates; bioreactor; salicylic acid; Hyoscyamus niger; metabolic diversity

\section{Introduction}

Roots of land plants exude small molecules, oligosaccharides, and proteins into the soil. The secreted compounds called root exudates serve multiple functions: they facilitate mobilization of soil nutrients [1-3], modulate the composition of microbial communities of the rhizosphere [4], and attract or repel soil micro- and mesofauna, affecting crop health and productivity [5]. Exudation of metabolites by roots is modulated by nutrient availability [6] and herbivore infestation [7]. Root exudates in turn serve as chemical signals for symbiotic and pathogenic microorganisms [8-10], soil herbivores and their predators [11].

Hairy roots are plant roots genetically transformed with the help of Agrobacterium rhizogenes that exhibit neoplastic growth and can be maintained indefinitely in sterile media without externally added phytohormones $[12,13]$. Because hairy root cultures consist entirely of differentiated roots and can be easily cloned, they are an ideal model for studies of root biochemistry $[14,15]$ and root-specific processes such as nodulation [16] and the synthesis of root-specific metabolites [17]. Hairy roots also proved useful in studies of interactions between crop plants and herbivores [18]. Biomass production in hairy root cultures is higher than in callus or suspension cultures, therefore hairy roots have been exploited for the production of plant secondary metabolites [12,19-22]. This strategy appears 
particularly promising for large-scale production of metabolites that are primarily synthesized in the roots, such as certain tropane alkaloids of medical interest [23] and glucosinolates with chemoprotective potential [24]. Optimization of the activity of desired biosynthetic pathways can further increase the efficiency of secondary metabolite production by hairy roots [25-28]. Recently genetic engineering of hairy roots received a boost by an adaptation of CRISPR/Cas9 technology for delivery by A. rhizogenes, which combines genome editing and hairy root induction into a single step [29]. Root exudates of hydroponically grown genetically engineered plants [30] as well as hairy roots of genetically modified plants [31,32] can also be used for the production of proteins for diagnostic and medical purposes such as antibodies, antigens for immunization, and growth factors. Optimization of the production system requires comparing multiple genetically enhanced lines because the efficiency of promoters used to drive heterologous gene expression varies among transformation events and even among different parts of the same plant [33]. Similarly, the expression of target genes and the yield of the desired products varies among hairy root lines $[21,28]$. Production of natural products by plants that have not been genetically engineered requires testing multiple accessions, too, because secondary metabolite synthesis varies among plant accessions in a way that is often not predictable based on the genotype [34,35]. Furthermore, cultivation conditions strongly affect production of plant secondary metabolites in hydroponics [36] as well as in hairy root cultures [21,37]. For these reasons, multiple cultures have to be grown in parallel during the optimization of hairy root-based production systems.

A major challenge for hairy root cultures is the supply of oxygen [38]. Different concepts have been pursued to improve oxygen supply to hairy roots in mid- and large-scale bioreactors [22,39]. Apart from conventional stirred bioreactors [40] and stirred bioreactors modified to reduce sharing damage [22,41], hairy root cultures have been grown in plastic sleeve reactors [42], bubble reactors [43], mist reactors [44,45], airlift reactors [46], and liquid-dispersed reactors [47]. The implementation of these concepts focused on midscale bioreactors for research on hairy roots and on industrial bioreactors. Micro and nano bubble generators have recently been introduced into bioreactor design [48], inspired by technologies for the delivery of oxygen and ozone in wastewater treatment [49]. The large surface of micro/nano bubbles as compared to conventional bubbles improves oxygen transfer efficiency. The drawback of micro and nano bubble generators is that they require high-pressure pumps. Furthermore, in airlift mode the liquid velocity decreases with bubble radius for bubbles smaller than $100 \mu \mathrm{m}$ [50]. Because micro bubbles are smaller than $50 \mu \mathrm{m}$ and nano bubbles are smaller than $200 \mathrm{~nm}$ [49], micro bubbles and especially nano bubbles are less suitable to drive liquid transfer in airlift bioreactors.

Small-scale inexpensive bioreactors for screening purposes and comparative studies are lacking, limiting our ability to address differences in the exudation potential of hairy root cultures derived from different plant accessions. Studies of the relationship between genetic polymorphism and secondary metabolite accumulation in plant tissues e.g., [34,51,52] and in root exudates [53] calls for comparative analysis of numerous plant accessions. Exclusion of the effect of bacteria and fungi colonizing plants as endophytes, pathogens, and inhabitants of the phyllosphere require axenic conditions, which can most conveniently be achieved in sterile hydroponic cultures. Lack of small and economical incubators for sterile hydroponics limits these studies.

Our laboratory studies the chemical diversity in sesame [34], extending the focus from seeds to roots and hairy roots and their exudates. In another project we study biological functions of salicylic acid, which may fulfill different roles in different species and even in different tissues of the same plant species. Salicylic acid is known to act as a signal of plant defense response in plant shoots [54] but we also found it in xylem sap of plants infected with a fungal pathogen [55] and in root exudates of healthy plants, where it facilitated mobilization of soil phosphorus [1]. Salicylic acid was also reported to participate on shaping microbial communities of the rhizosphere [56], serving as a signal in interorganismal interactions. Comparative analysis of salicylic acid exudation by different plant accessions requires growing multiple sterile cultures in parallel. In another project in our laboratory we study replant disease of roses. This project relies on the analysis of root exudates because we pursue a 
hypothesis explaining the disease by the effects of certain components of root exudates accumulating in the rhizosphere of roses [57]. Root exudates of rose accessions known to suffer from replant disease have to be collected under sterile conditions, their components identified and the phytotoxicity of these components determined. Progress in all three projects has been hampered by the lack of small bioreactors for sterile hydroponics and hairy root cultures.

The objective of this work was to develop a small-volume, low-cost bioreactor and validate its suitability for hydroponic cultures of Brassica napus and Rosa canina, for growing hairy roots of Hyoscyamus niger and Sesamum indicum and for the collection of root exudates and hairy root exudates suitable for HPLC analysis.

\section{Materials and Methods}

\subsection{Bioreactor Design}

The concept and operating principle of the bioreactor are shown on Figure 1. The body of the bioreactor is connected to an external draft tube. In airlift aeration mode, air bubbles released from a glass frit at the bottom of the draft tube saturate medium with oxygen and drive nutrient medium flow between the draft tube and the reactor body (Figure 1A). The aeration mode can be switched from airlift to bubble mode by attaching air supply to the port on the top of the draft tube and closing the port at the bottom of the draft tube (Figure 1A). The facility to control the aeration mode by connecting air supply to an appropriate port of the draft tube with remaining parts of the reactor unchanged is a distinctive feature of the design.

A

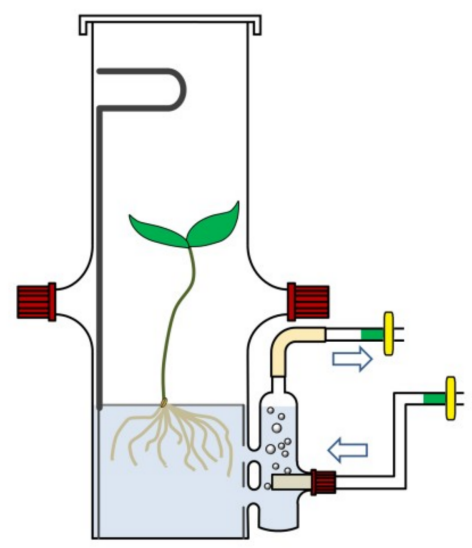

B

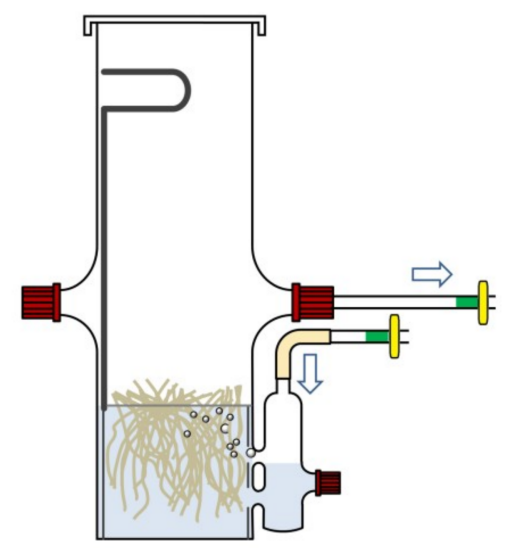

Figure 1. Scheme of bioreactor operating in airlift mode (A) and bubble aeration mode (B).

The second part of the reactor is an internal cylinder inserted into the reactor body. The internal cylinder holds a supporting disk that carries plants or hairy roots. The disk, which loosely resides on the perimeter of the cylinder (Figure 2A, part 1), can be cut from a perforated plate or mesh made of plastic, stainless steel or other materials. The internal cylinder is equipped with a handle for easy removal to facilitate harvesting cultivated material under a sterile bench.

All components and working principles of the bioreactor have been known but the double function of the external draft tube and the way how the bioreactor is assembled from common glass components (see also the following section) are new to this design. 
A

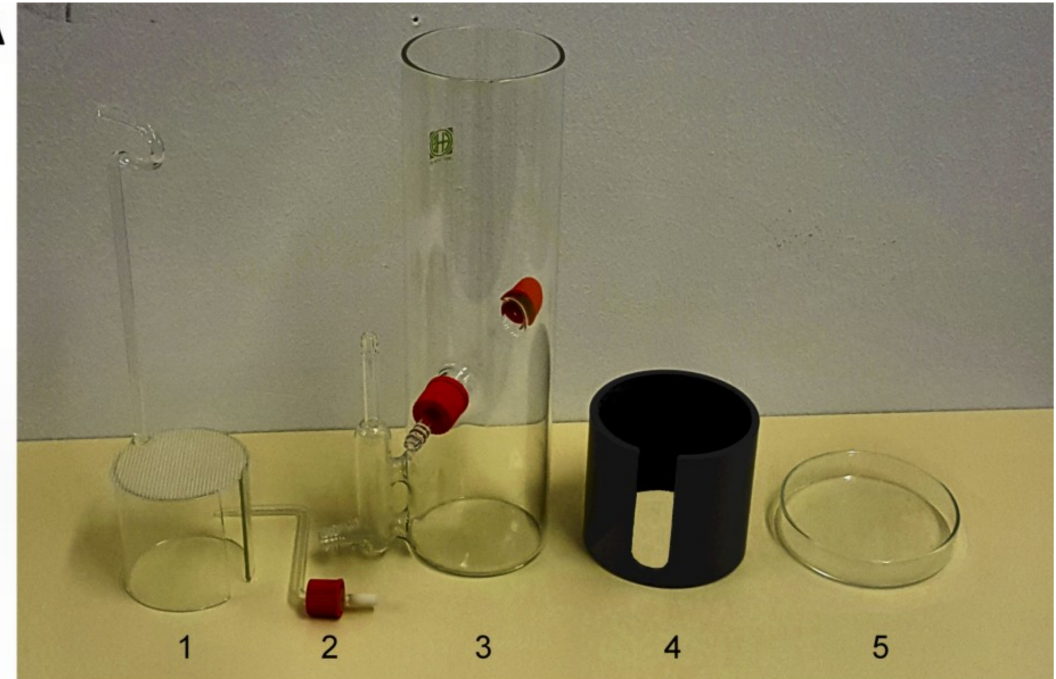

B

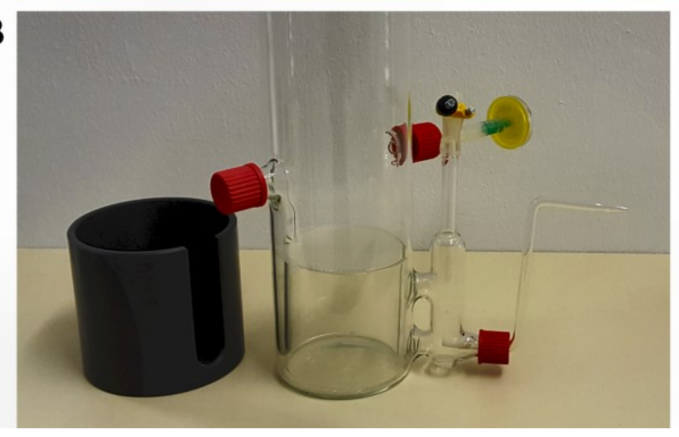

C

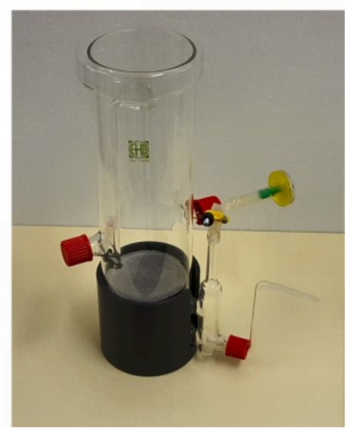

Figure 2. Bioreactor for sterile hydroponics and hairy root cultures. (A) Components of the bioreactor are (1) internal cylinder with a polypropylene mesh, (2) connector for air supply with a glass frit, (3) reactor body with an attached draft tube, (4) light-shielding external cylinder made of polyvinyl chloride, and (5) Petri dish serving as a lid. (B) Detailed view of a bioreactor fitted with an air supply tube. (C) Full view of an assembled bioreactor.

\subsection{Fabrication of the Bioreactor}

The components of the bioreactor are shown in Figure 2A. The reactor body with an attached draft tube (Figure 1A, part 3) and an internal glass cylinder (Figure 1A, part 1) were made of glass tubes. The light-shielding external cylinder (Figure 1A, part 4) was cut from a polyvinyl chloride tube. The body of the reactor had an external diameter of $90 \mathrm{~mm}$, a height of $270 \mathrm{~mm}$ and a wall thickness of $2.5 \mathrm{~mm}$. The draft tube of $18 \mathrm{~mm}$ diameter and $75 \mathrm{~mm}$ height was connected with the reactor body at two sites via glass tubes as shown in Figure 2A, part 3 and Figure 2B. It was furnished with two connectors: a bottom connector accommodated a glass tube with a frit supplying air in airlift operation mode (Figure 2A, part 2). The top connector served as air supply in bubble aeration mode. The body of the reactor was equipped with two ports for the collection of volatiles, for an optional $\mathrm{CO}_{2}$ supply or for air exhaust in bubble aeration mode. Ports that were not in use were closed with screw cups. The internal cylinder had a diameter of $84 \mathrm{~mm}$ and a height of $70 \mathrm{~mm}$. The cylinder held a polypropylene mesh, which rested on its perimeter as a support for plants or hairy roots during cultivation (Figure 2A, part 1). A handle attached to the internal cylinder was made of a glass rod of a diameter of $5 \mathrm{~mm}$. A clearance of $20 \mathrm{~mm}$ width was cut into the internal cylinder (Figure 2A, part 1) at a position facing the draft tube (Figure $1 \mathrm{~A}, \mathrm{~B}$ ) to allow exchange of growth medium between the body of the reactor and the draft tube and to facilitate air supply in bubble aeration mode. A glass Petri dish with an internal diameter of 91-92 mm served as a lid (Figure 2A, part 5). 


\subsection{Operation of the Bioreactor}

For sterile hydroponics, the reactor was filled with nutrient solution just to the level of the mesh supporting the plants, which required about $450 \mathrm{~mL}$ medium per reactor. The reactor was operated in airlift mode with the upper port of the draft tube closed with a filter and the air supply attached to the lower port of the draft tube. The air flow was $480 \mathrm{~mL} / \mathrm{min}$.

For growing hairy roots, the reactor was steam-sterilized and filled with nutrient solution to the level of the supporting mesh or above, depending on whether aerial growth was desirable. Hairy root cultures are known to suffer from inhomogeneous growth and inferior yields when grown in air-lift reactors [46], therefore bubble aeration mode was used. The air flow was $670 \mathrm{~mL} / \mathrm{min}$. In some experiments, the lid was loosely place over the reactor, both ports of the body of the reactor were closed with screw cups to and the flow of air leaving the reactor below the led prevented contamination. In other experiments, the lids were sealed in place with Parafilm and one of the ports of the reactor body serving as an air exhaust was equipped with a hydrophobic sterile filter (Midisart, Sartorius, Göttingen, Germany).

Low-cost aquarium pumps connected to the reactors via Midisart filters were used as air supply. The reactors were operated in an environmental chamber (Mytron, Bio-u. Solartechnik GmbH, Heiligenstadt, Germany) set to a constant temperature (varying among the experiments as described in Section 3) and $12 \mathrm{~h}$ light per day. We have not measured oxygen concentration in growth medium because the concentration within in the bulk of hairy roots is likely to vary with the location of the probe and accurate methods for the determination of volumetric mass transfer coefficient, such as a rapid switch between input gases with different oxygen concentrations or the dynamic pressure method [58], were beyond the scope of this work.

\subsection{Plant Material}

Seeds of Brassica napus var. napus, rapid cycling accession were provided by P.H. Williams (Crucifer Genetics Cooperative at the University of Wisconsin-Madison, WI, USA). Sterile cuttings of rose plants (Rosa canina L., variety "The Fairy") were purchased from Institut für Pflanzenkultur (Schnega, Germany). Accessions of Hyoscymus niger and Sesamum indicum used in this study are listed in Tables 1 and 2.

Table 1. Hyoscyamus niger.

\begin{tabular}{cccc}
\hline Label & Origin & Year & Source \\
\hline Iraq & Iraq, Daray Mar & 2014 & Collected by ZJK \\
Iran & Iran, Isfahan & 2015 & Pakan Bazr * \\
Germany & Germany, Göttingen & 2016 & Botanical garden \\
\hline \multicolumn{4}{c}{ * Seeds were provided by Pakan Bazr company, Iran. }
\end{tabular}

Table 2. Sesamum indicum accessions.

\begin{tabular}{cccc}
\hline Label & Origin & Year ${ }^{*}$ & Accession \\
\hline India & India, Hyderabad & 2004 & Acc. 92-2918 \\
Japan & Japan & 2004 & Acc. 92-3030 \\
Sumer S2b & Iraq, Erbil & 2014 & Sumer S2b \\
\hline
\end{tabular}

* Year of the acquisition of seeds from the collection. ${ }^{* *}$ Centro Nacional Inv. Agropecuarias (CENIAP) Germplasm Bank, Venezuela. ${ }^{* *}$ Ministry of Agriculture, Regional Government of Iraqi Kurdistan, General Directorate of Research, Extension and Training.

\subsection{Analysis of Root Exudates by HPLC-DAD}

Growth medium was filtered through paper filter to remove root fragments and concentrated in a rotary evaporator to $1 / 4$ volume. The concentrate was extracted with equal volume of ethyl acetate, the watery phase was acidified with $1 \%$ acetic acid and extracted with a new portion of ethyl acetate. 
The extracts were combined and solvent was removed in vacuum. Three biological replicates were prepared and extracts of culture medium incubated in bioreactors under the same conditions yet without plants were used as blanks. Thirty-three milligrams of dried residue were suspended in $1.5 \mathrm{~mL}$ of methanol/water (1:1) and sonicated for $5 \mathrm{~min}$. The suspension was filtered through $0.4 \mu \mathrm{m}$ filters and $10 \mu \mathrm{l}$ were injected into HPLC system 1290 Infinity II with a DAD detector G7117B (Agilent, Darmstadt, Germany) equipped with a Varian Polaris C18 Ether column ( $3 \mu \mathrm{m}$ particle size, $2 \times 100 \mathrm{~mm}) \mathrm{kept}$ at $35{ }^{\circ} \mathrm{C}$. LC-MS grade methanol and distilled water were acidified with $0.1 \%$ formic acid and used for gradient elution from $95 \%$ to $0 \%$ water in $20 \mathrm{~min}$ at a flow rate of $0.2 \mathrm{~mL} / \mathrm{min}$. Light absorption spectra were recorded from 220 to $550 \mathrm{~nm}$ and chromatograms at the wavelengths 229, 254, 280, and $320 \mathrm{~nm}$ were monitored. The bandwidth was set to $4 \mathrm{~nm}$ and the reference wavelength to $600 \mathrm{~nm}$.

\subsection{Induction of Hairy Roots}

Agrobacterium rhizogenes ATCC 15834 was grown in YEB medium [59] (0.5\% peptone, $0.1 \%$ yeast extract, $0.5 \%$ meat extract, $0.5 \%$ sucrose, $0.049 \% \mathrm{MgSO}_{4} .7 \mathrm{H}_{2} \mathrm{O}, 1.5 \%$ agar, $\left.\mathrm{pH} 6.8-7.2\right)$, at $25-26{ }^{\circ} \mathrm{C}$ for $36 \mathrm{~h}$ in the dark on a rotatory shaker $(100 \mathrm{rpm})$. The cells were harvested by centrifugation at $5000 \times \mathrm{g}$ for $15 \mathrm{~min}$, re-suspended in MS medium (Murashige and Skoog medium, [60]) and set to the $\mathrm{OD}_{600}$ of 1.3. Leaves were harvested from four weeks old plants grown under sterile conditions from superficially sterilized seeds, cut into squares of $1 \times 1 \mathrm{~cm}$, placed on $1 / 2 \mathrm{MS}$ medium solidified with $0.7 \%$ agar and co-cultivated with $A$. rhizogenes for $30 \mathrm{~min}$ at room temperature. After the incubation, leaf segments were dried with sterile filter paper and placed onto phytohormone-free MS medium supplemented with $2.2 \%(\mathrm{w} / \mathrm{v})$ sucrose and solidified with $0.7 \%$ agar and incubated in darkness at $22{ }^{\circ} \mathrm{C}$. After $72 \mathrm{~h}$ the segments were transferred onto fresh medium supplemented with cefotaxime at $500 \mathrm{mg} / \mathrm{L}$. About two weeks after the inoculation the formation of the first roots was observed. One root was excised from each leaf segment. These roots were treated as hairy root clones. The roots were subcultured each 30 days. After six passages, sterile hairy roots were transferred to antibiotic-free medium.

\subsection{Analysis of Hairy Root Exudates by HPLC-ELSD}

Three biological replicates were prepared and culture medium was used as a blank. The samples were analyzed by HPLC using Agilent 1290 Infinity II system coupled to an Agilent 1260 evaporative light-scattering detector (ELSD) (Agilent, Darmstadt, Germany). For the ELSD, the evaporation temperature was set to $42{ }^{\circ} \mathrm{C}$, the nebulizer temperature to $40{ }^{\circ} \mathrm{C}$ and the nebulizer $\mathrm{N}_{2}$ flow amounted $1.6 \mathrm{~L} / \mathrm{min}$. A Varian Polaris C18 Ether column $(3 \mu \mathrm{m}$ particle size, $2 \times 100 \mathrm{~mm})$ was used for separation. The column temperature was kept at $35^{\circ} \mathrm{C}$ and samples of $40 \mu \mathrm{L}$ were injected. LC-MS grade methanol obtained from Chemsolute (Th. Geyer, Renningen, Germany) and distilled water purified by Arium Pro water purification system (Sartorius, Göttingen, Germany) were acidified with $0.1 \%$ LC-MS grade formic acid (Honeywell Fluka, Bucharest, Romania) and used for gradient elution from $90 \%$ to $2 \%$ water in $15 \mathrm{~min}$ at a flow rate of $0.2 \mathrm{~mL} / \mathrm{min}$.

\subsection{Analysis of Salicylic Acid Content in Hairy Root Exudates by HPLC-MS}

The samples were analyzed by HPLC using an Agilent 1290 Infinity II system (see Section 2.7 for details) with the column maintained at $35^{\circ} \mathrm{C}$. LC-MS grade methanol and distilled water were acidified with $0.1 \%$ formic acid and used for gradient elution from $95 \%$ to $0 \%$ water in $20 \mathrm{~min}$ at a flow rate of $0.2 \mathrm{~mL} / \mathrm{min}$. The HPLC system was coupled to an Agilent 6545 QTOF equipped with a Jet Stream source operated with the following settings: drying gas temperature $320^{\circ} \mathrm{C}$, drying gas flow $8 \mathrm{~L} / \mathrm{min}$, nebulizer pressure $35 \mathrm{psig}$, sheath gas temperature $350{ }^{\circ} \mathrm{C}$, and sheath gas flow $11 \mathrm{~L} / \mathrm{min}$. Negative mode data were acquired with three spectra pre second recorded from 100 to $1700 \mathrm{~m} / \mathrm{z}$. External calibration was prepared from salicylic acid solutions in 50\% methanol. 


\subsection{Primer Design and Sequence Analysis}

The sequence of $\operatorname{Tr} 2$ gene from Hyoscyamus niger (accession No. AB026545.1, tropinone reductase II) was used for the design of primers for PCR and sequencing. The primers (forward primer TCTGA ACGAG AAGAG TTTAT GAAGA and reverse primer AAGTG ATAAG CAGCC TCAAA GT) amplified a segment of the gene from $1543 \mathrm{nt}$ to $2237 \mathrm{nt}$, producing an amplicon of $695 \mathrm{bp}$. PCR products were sequenced by Sanger method from both ends (Macrogen Europe, Amsterdam, The Netherlands), the complementary reads were aligned and ambiguities were resolved by inspection of the electropherograms. An alignment of the sequences from $1592 \mathrm{nt}$ to $2165 \mathrm{nt}$ (original numbering of AB026545.1) was constructed using Clustal W implemented in MEGA 10.0.4 [61] and used to calculate nucleotide differences per $1000 \mathrm{bp}$.

\section{Application Examples}

The performance of the bioreactor was tested by growing two plant species in sterile hydroponics and collecting root exudates; by comparing growths rate of hairy roots generated from two plant species; and by collecting and analyzing hairy root exudates.

\subsection{Growing Oilseed Rape (Brassica napus L.) in Sterile Hydroponics}

Ten surface-sterilized seeds of a rapid cycling variety of Brassica napus were placed into bioreactors filled with half-concentrated MS medium [60] without sucrose and operated in airlift mode. The plants grown at $24^{\circ} \mathrm{C}$ for three weeks have not shown any chloroses or other negative effects of cultivation in restricted space and at high air humidity [62,63] (Figure 3).

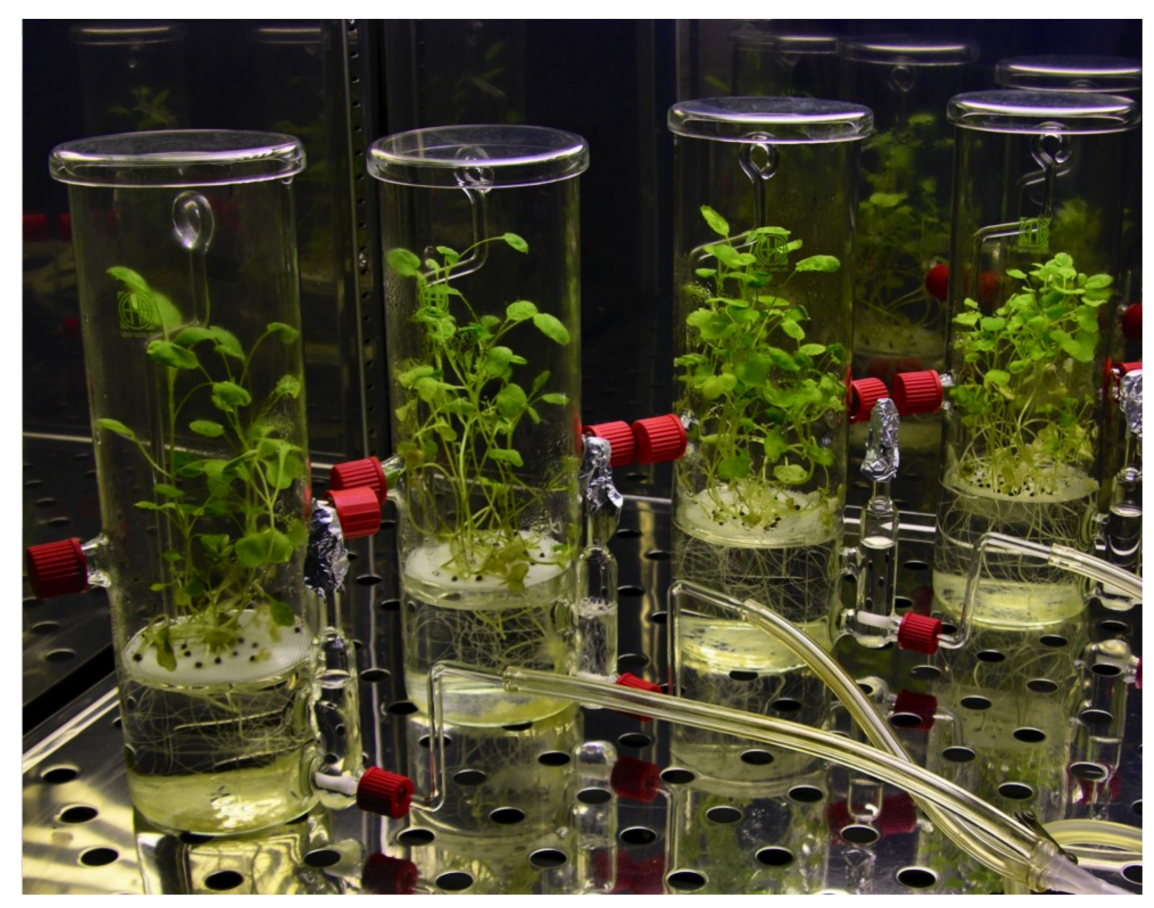

Figure 3. Oilseed rape (Brassica napus L.) grown in sterile hydroponics. Ten plants per bioreactor were grown in $0.5 \times$ MS medium for three weeks at $24{ }^{\circ} \mathrm{C}$ with $12 \mathrm{~h}$ light per day. External light-shielding cylinders were removed for the photography.

\subsection{Growing Rose Plants (Rosa canina L.) in Sterile Hydroponics}

Rose cuttings were adapted to light for 3 days at $20^{\circ} \mathrm{C}$ under long day conditions before transfer to bioreactors. A single rose plant per bioreactor was cultivated for six weeks in half-concentrated MS 
medium with $2 \mathrm{~g}$ sucrose per liter and $\mathrm{pH}$-value set to 5.8 with $\mathrm{KOH}$ in bioreactors in the airlift mode (Figure 4). The plants were grown at $20^{\circ} \mathrm{C}$ for four weeks.

All roots formed on cuttings were adventitious by definition, yet strong white roots penetrating the plastic mesh and growing downwards resembled primary and seminal roots, while dark roots growing on the surface of the mesh and supporting the plants in a vertical position resembled crown roots (Figure 4). The roots growing downwards in medium remained white for the entire cultivation period without signs of necroses, which typically occur in medium solidified with agar (A. Sirrenberg, unpublished observation) due to replant disease syndrome [57].

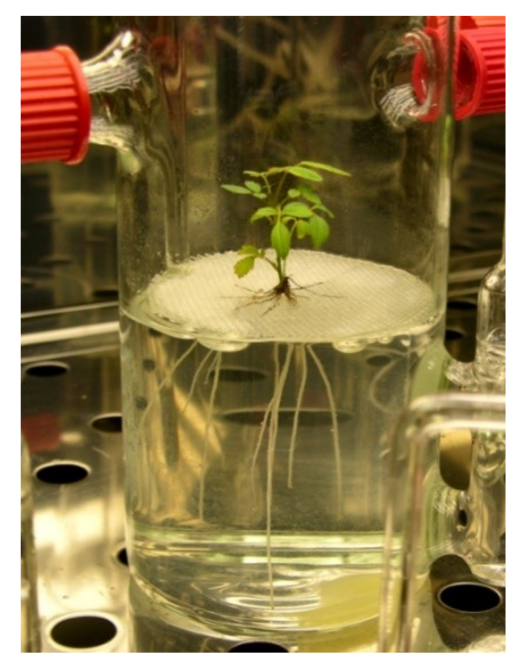

Figure 4. Rose plant (Rosa canina L.) growing in sterile hydroponics in $0.5 \times$ Murashige-Skoog medium supplemented with $2 \%$ sucrose in a bioreactor operated in airlift mode.

\subsection{Collection and Analysis of Root Exudates of Rose (Rosa canina L.) by HPLC-DAD}

Rose plants (Rosa canina L.) were grown in medium with $2 \%$ sucrose for the collection of root exudates as shown in Figure 4. After four weeks, plants were removed and medium was filtered and stored at $-20^{\circ} \mathrm{C}$. For the chemical analysis of root exudates, exclusion of microbial contamination is crucial because microorganisms use the exudates as nutrients and contaminate the medium with their own metabolites. In 11 experiments with 3 to 6 parallel cultures each, contamination occurred in less than $5 \%$ cultures. A total of $13.2 \mathrm{~L}$ medium were collected, concentrated in vacuum and extracted with ethyl acetate (see Section 2.5.) for the analysis and purification of selected components of root exudates. Figure 5 shows a typical result of the analysis of root exudates of rose plants collected in bioreactors by HPLC coupled to a UV detector (HPLC-DAD).

\subsection{Growing Hairy Roots of Hyoscyamus niger and Sesamum indicum}

To compare the yield of hairy roots in the bioreactor and in shaken flask cultures, hairy roots originating from three accession of each Hyoscyamus niger and Sesamum indicum were cultivated in bioreactors and in shaking flasks. The cultures were initiated by $100 \mathrm{mg}$ of hairy roots cut into $1 \mathrm{~cm}$-long pieces. Culture flasks of $300 \mathrm{~mL}$ volume contained $50 \mathrm{~mL}$ MS medium supplemented with $2.5 \%$ sucrose. The cultures were grown on a shaker at $90 \mathrm{rpm}$ in the dark at $25^{\circ} \mathrm{C}$ and in bioreactors operated in bubble mode with an air flow of $670 \mathrm{~mL} / \mathrm{min}$ (Figure 6).

After 30 days, hairy roots were harvested by filtration, blotted dry with sterilized filter paper, frozen at $-20^{\circ} \mathrm{C}$ overnight and lyophilized for $72 \mathrm{~h}$. Then the dry weight of hairy roots was determined (Figure 7). 
A

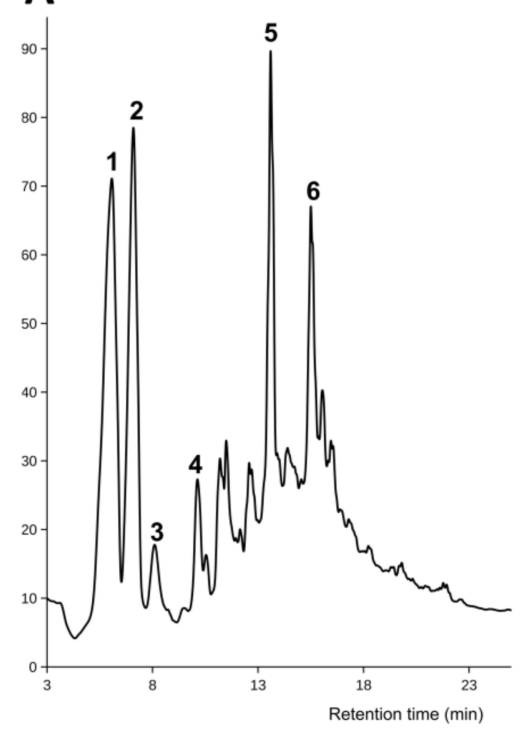

B
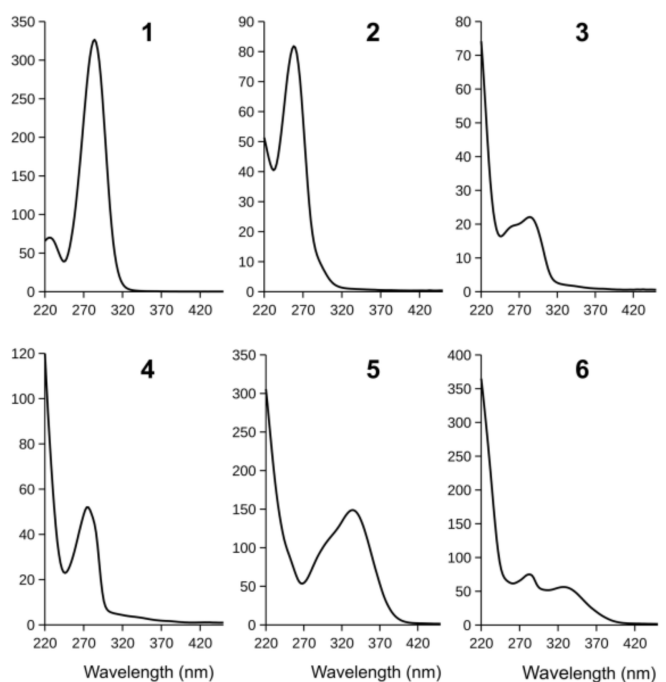

Figure 5. HPLC analysis of root exudates of rose (Rosa canina L.) collected in the bioreactor. (A) HPLC chromatogram of root exudates separated on a reverse-phase column, eluted with a methanol gradient and detected by light absorption at $254 \mathrm{~nm}$. (B) UV absorption spectra of major phenolic compounds recorded using a diode array detector coupled to HPLC.

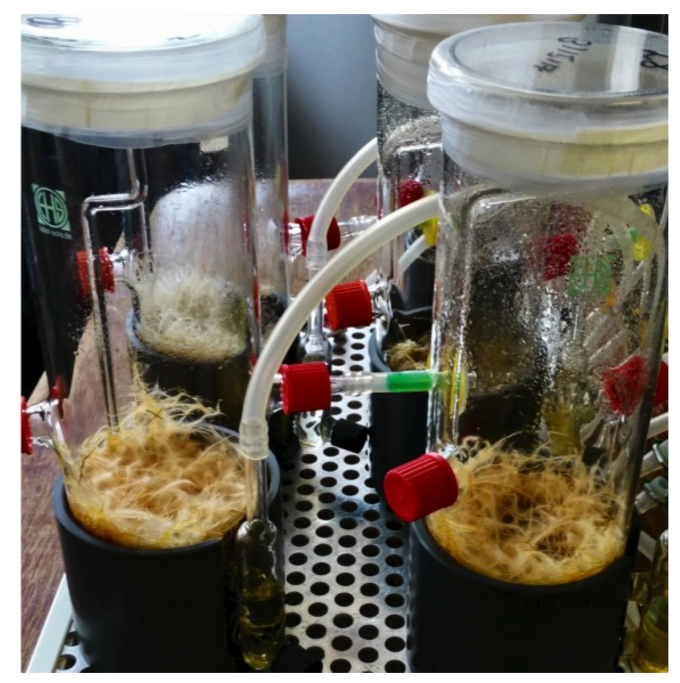

Figure 6. Hairy root cultures generated from several accessions of Hyoscyamus niger in bioreactors operated in a bubble aeration mode.

The biomass of hairy roots varied among accessions but we have not investigated these differences statistically because our purpose was to compare the performance of the bioreactor with that of flask cultures. In Sesamum indicum, the biomass of hairy roots grown in bioreactors was larger than or similar to the biomass harvested from shaking flasks. In Hyoscyamus niger, more biomass was harvested from bioreactors than from flasks in all three plant accessions studied (Figure 7). We assume that better supply of oxygen in the bioreactor was the cause of these differences.

\subsection{Collection and Nontargeted Analysis of Hairy Root Exudates of Sesamum indicum}

Growth medium of hairy root cultures grown as described above was cleared by centrifugation for $10 \mathrm{~min}$ at $2900 \times \mathrm{g}$ to remove root fragments. The medium was used for HPLC-ELSD analysis 
without cleanup. Figure 8 shows a comparison of HPLC-ELSD chromatograms of hairy root exudates obtained from the bioreactor and from a flask culture for one accession of sesame.

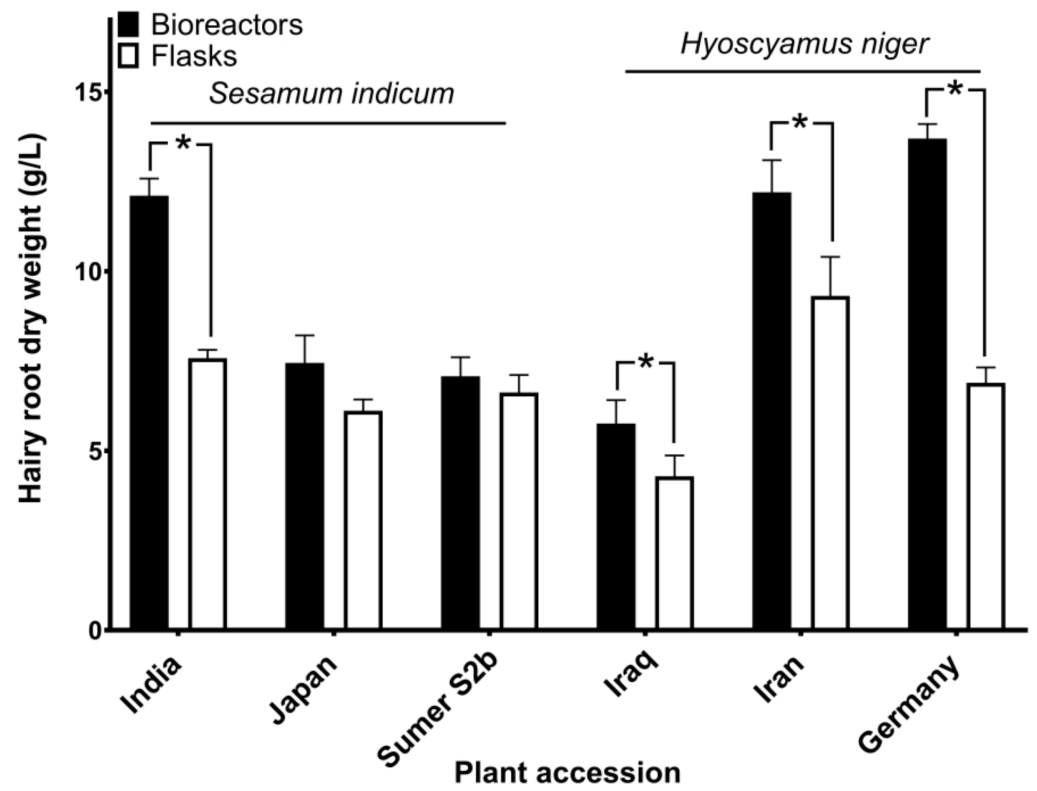

Figure 7. Biomass of hairy roots grown in bioreactors and flask cultures. Hairy root cultures originating from three accessions of each plant species were grown for 30 days and the dry weight of harvested biomass was determined. Asterisks denote significant differences between means (two-tailed $t$-test, $\mathrm{n}=3, \mathrm{p}<0.05)$.

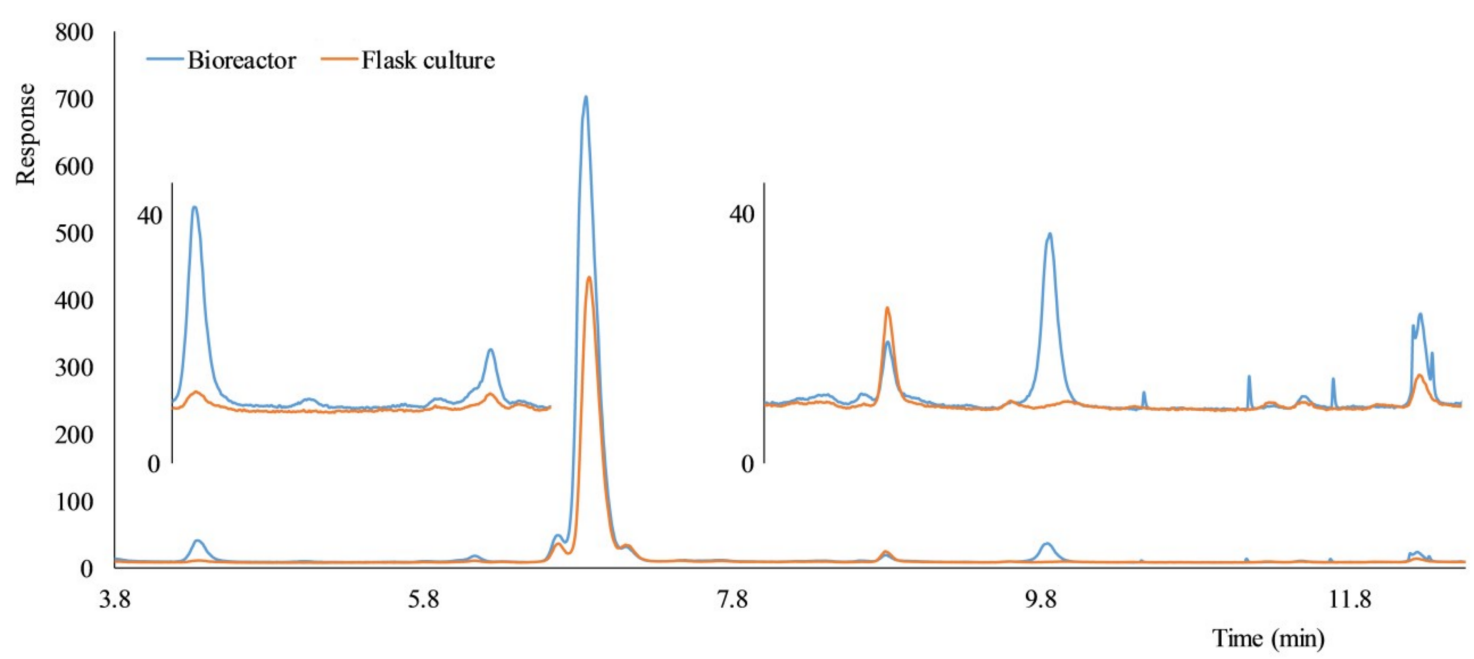

Figure 8. Comparison of HPLC-ELSD chromatograms of hairy roots exudates of Sesamum indicum (accession Japan) grown in the bioreactor and a flask culture. Culture fluid clarified by centrifugation was directly analyzed by HPLC-ELSD.

The amount and diversity of hairy root exudates obtained from a bioreactor were higher than the amount and diversity of exudates obtained from a shaking flask culture (Figure 8). Better oxygen supply in the bioreactors was the likely reason. Most importantly, all metabolic signals recorded in exudates from the flask culture were also found in exudates from the bioreactor, indicating that that few (if any) metabolites will be lost by replacing culture flasks with bioreactors. 


\subsection{Analysis of Salicylic Acid Exudation by Hairy Roots of Hyoscyamus niger}

To test the suitability of the bioreactor for comparative studies of salicylic acid exudation by hairy roots, hairy root cultures generated from three accessions of Hyoscyamus niger and Sesamum indicum were grown in $0.5 \times$ MS medium with $2.5 \%$ sucrose in bioreactors operated in bubble mode and in shaken flasks. After 30 days, growth medium was collected, extracted with ethyl acetate and the extracts were analyzed by HPLC-MS. The results are shown in Figure 9.

Hairy roots of Hyoscyamus niger exuded salicylic acid into growth medium in amounts varying from $2 \mu \mathrm{g} / \mathrm{L}$ to $60 \mu \mathrm{g} / \mathrm{L}$, while hairy root exudates of Sesamum indicum has not secreted detectable amounts of salicylic acid (data not shown). Cultivation conditions strongly affected the concentration of salicylic acid accumulating in nutrient solution. Hairy roots of one plant accession secreted larger amounts of salicylic acid in bioreactors, while hairy roots on another accession secreted much large amounts of salicylic acid in shaking flasks (Figure 9). This surprising result indicates that the response of salicylic acid pathway to environmental cues varies among populations of the same plant species. We speculate that these differences reflect selection pressures exerted by different environments on the plants. The result corroborates our assumption that studying differences in salicylic acid production among plants with different life histories may shed light into biological functions of this multifaceted metabolite.

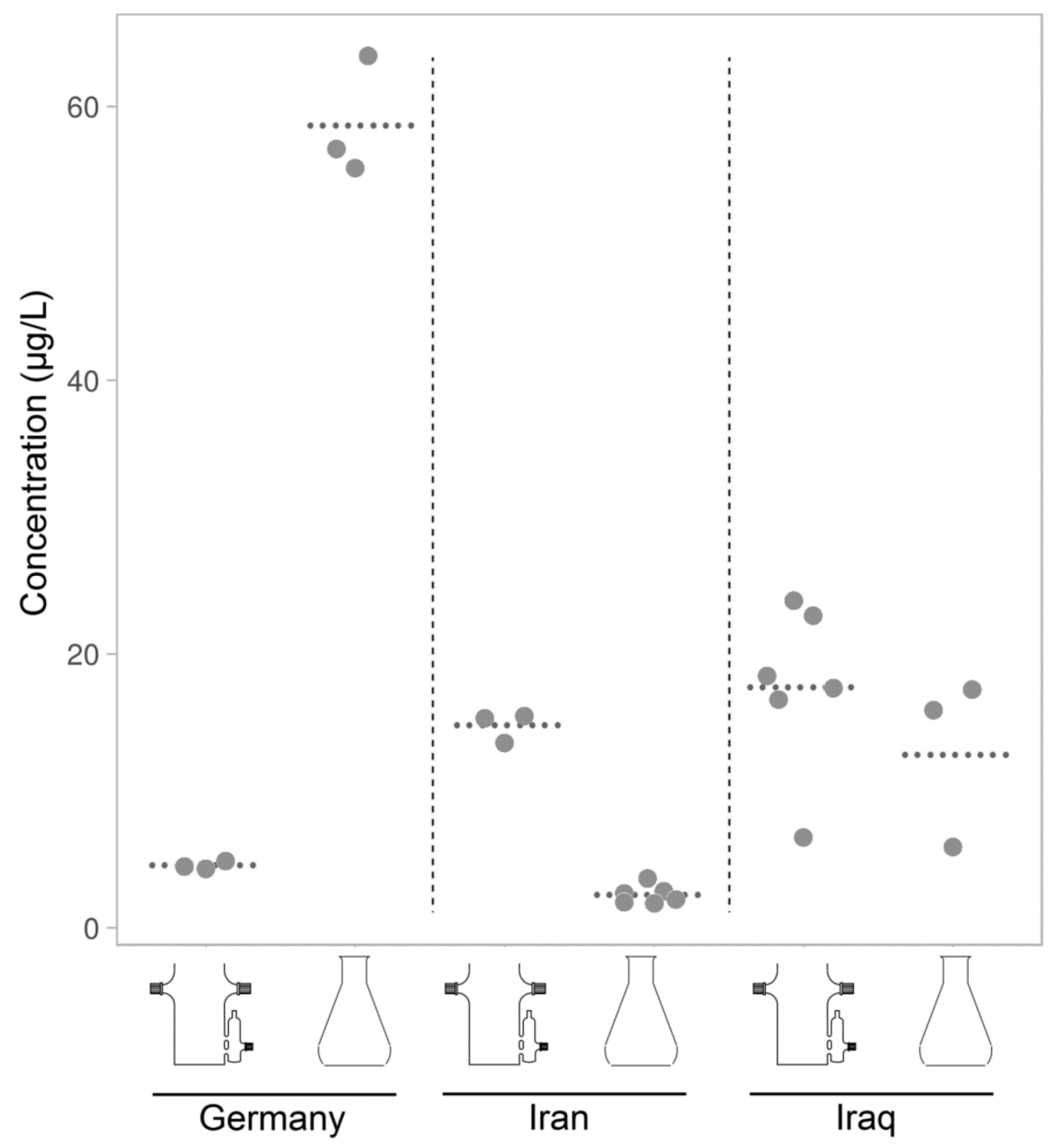

Figure 9. Salicylic acid accumulated in nutrient solution of hairy root cultures derived from three accessions of Hyoscyamus niger (designated Iraq, Iran and Germany) and grown in bioreactors and in shaking flasks for three weeks. Dotted lines show the means. 
As far as we are aware, secretion of salicylic acid by hairy roots has not been reported yet. Adding salicylic acid to culture medium of hairy roots was used to stimulate the synthesis of alkaloids [64], including hyoscyamine and further tropane alkaloids $[65,66]$, which are also produced by Hyoscyamus niger. The interplay between the secretion of salicylic acid and stimulation of alkaloid synthesis by externally added salicylic acid adds to the complexity of biological roles and effects of salicylic acid in plants.

\subsection{Nontargeted Analysis of Hairy Root Exudates in Hyoscyamus niger: Comparison to Shaking Flasks}

Hairy root cultures of $H$. niger were grown in the bioreactor operated in a bubble mode and in traditional shaken flask cultures. After 30 days, growth media were collected, extracted with ethyl acetate and the extracts were analyzed by HPLC. Because the components of the exudates were unknown, an evaporative light scattering detector (ELSD) was used, which allows for an approximate comparison of concentrations without authentic standards because the response factor of the detector is largely independent of the chemical structure of the analyte [67].

The results of the analysis of hairy root exudates by HPLC-ELSD are shown in Table 3 . The average standard error of the intensity of HPLC signals in exudates obtained from bioreactors was $20 \%$, compared to the average standard error of $28 \%$ for exudates from shaken flasks. Thus the reproducibility of the composition of hairy root exudates collected in bioreactors appears higher than the reproducibility of exudates collected in shaking flasks. The total intensity of HPLC-ELSD signals detected in exudates from bioreactors (average total per accession of 9024) was 1.6-times larger than the total intensity of signals from shaking flasks (average total per accession of 5692), indicating that hairy roots exuded larger amounts of metabolites in bioreactors as compared to shaking flasks.

Table 3. Exudates of hairy roots of Hyoscyamus niger collected in bioreactor and flask cultures. The exudates were analyzed by HPLC-ELSD. Only metabolites present in all three replicates were recorded.

\begin{tabular}{lccccccc}
\hline $\begin{array}{c}\text { Accession } \\
\text { Metabolite }\end{array}$ & \multirow{2}{*}{ RT * } & \multicolumn{2}{c}{ Iran } & \multicolumn{2}{c}{ Germany } & \multicolumn{2}{c}{ Iraq } \\
Bioreactor & Flasks & Bioreactor & Flasks & Bioreactor & Flasks \\
\hline Compound 1 & 3.6 & N.d. & $224 \pm 191$ & N.d. & N.d. & N.d. & N.d. \\
Compound 2 & 4.3 & $41 \pm 4$ & N.d. & $41 \pm 4$ & N.d. & N.d. & $100 \pm 125$ \\
Compound 3 & 6.1 & $128 \pm 18$ & $20 \pm 2$ & $24 \pm 1$ & $32 \pm 2$ & $30 \pm 4$ & $41 \pm 2$ \\
Compound 4 & 6.8 & $12,500 \pm 600$ & $2300 \pm 00$ & $5700 \pm 490$ & $5100 \pm 200$ & $7000 \pm 300$ & $5900 \pm 200$ \\
Compound 5 & 7.7 & $29 \pm 5$ & N.d. & N.d. & N.d. & N.d. & N.d. \\
Compound 9 & 9.5 & $40 \pm 8$ & N.d. & N.d. & N.d. & $35 \pm 9$ & N.d. \\
Compound 10 & 9.7 & $75 \pm 29$ & $750 \pm 350$ & $1300 \pm 650$ & $485 \pm 175$ & N.d. & $1750 \pm 490$ \\
Compound 11 & 9.9 & $42 \pm 29$ & N.d. & N.d. & N.d. & N.d. & N.d. \\
Compound 12 & 10.5 & N.d. & N.d. & $32 \pm 2$ & $52 \pm 13$ & N.d. & $120 \pm 30$ \\
Compound 13 & 11.1 & N.d. & N.d. & $51 \pm 18$ & $110 \pm 41$ & N.d. & $67 \pm 2$ \\
Compound 14 & 11.3 & N.d. & N.d. & $21 \pm 5$ & N.d. & N.d. & N.d. \\
Compound 17 & 14.8 & N.d. & $87 \pm 8$ & N.d. & N.d. & N.d. & N.d. \\
\hline \multicolumn{7}{c}{ Retention time [min]. ** Signal intensity [peak area] as mean s.d. } &
\end{tabular}

\subsection{Metabolic Diversity of Hairy Root Exudates and Genetic Diversity in Hyoscyamus niger}

One of the goals of studies of chemical diversity in plants is to assess the relationship between metabolic and genetic diversity. The results of a limited number of studies indicated that patterns of genetic and metabolic similarity may be incongruent $[34,35,68]$. The bioreactor designed in this work will facilitate comparison of root exudates and/or hairy root exudates for plant accessions with known genetic relationships. To demonstrate this approach on hairy root exudates of Hyoscyamus niger (see Section 3.7.), we determined pairwise Euclidean distances among normalized metabolic profiles of hairy root exudates of three varieties of $H$. niger. To determine the effect of cultivation system on the composition of the exudates, we also determined the distances between metabolic profiles of each variety grown in bioreactors and in shaking flasks. 
The results showed that the differences among accessions were of the same magnitude as differences due to cultivation conditions (Figure 10). To obtain a first insight into the relationship between metabolic profiles and genetic distances among plant accessions from which the hairy roots were derived, the third intron of the Tr2 gene was sequenced. Tr2 encodes tropinone reductase, which is involved in the synthesis of tropane alkaloids. The sequences were deposited in NCBI under Nos. MN017172 (accession Iraq), MN017173 (accession Iran), and MN017174 (accession Germany). The number of nucleotide differences per $1000 \mathrm{bp}$ between the sequences from the accessions Iraq/Iran and Iraq/Germany were 21 and 23, respectively, while the accessions Iran and Germany differed in only 2 nucleotides. Thus the accessions Iran and Germany appeared more closely related than each of them to the accession Iraq. The similarity between sequences of a Tr2 gene of the accessions Iran and Germany was not reflected by the similarities of metabolic profiles of their hairy root exudates (Figure 10). Depending on cultivation conditions, the most similar profiles were Iraq/Germany and Iraq/Iran. The discrepancy between metabolic and genetic similarity is in line with the results of previous studies in other plant species $[34,35,68]$. In contrast, chemical profiles and microsatellite markers in Citrus aurantium were correlated [69]. Hyoscyamus niger is an attractive model to study the relationship between metabolic and genetic diversity in plants because it is a source of medicinally useful tropane alkaloids [70]. Attempts to produce tropane alkaloids in hairy root cultures of Hyoscyamus niger began decades ago [71] yet nothing is known about the genetic variation within the species. The availability of small-scale, inexpensive bioreactors will allow for comprehensive sampling of metabolic diversity in hairy root cultures of $H$. niger, which will facilitate selection of accessions for production purposes and enable studies of the relationship between metabolic and genetic diversity in this medical plant.

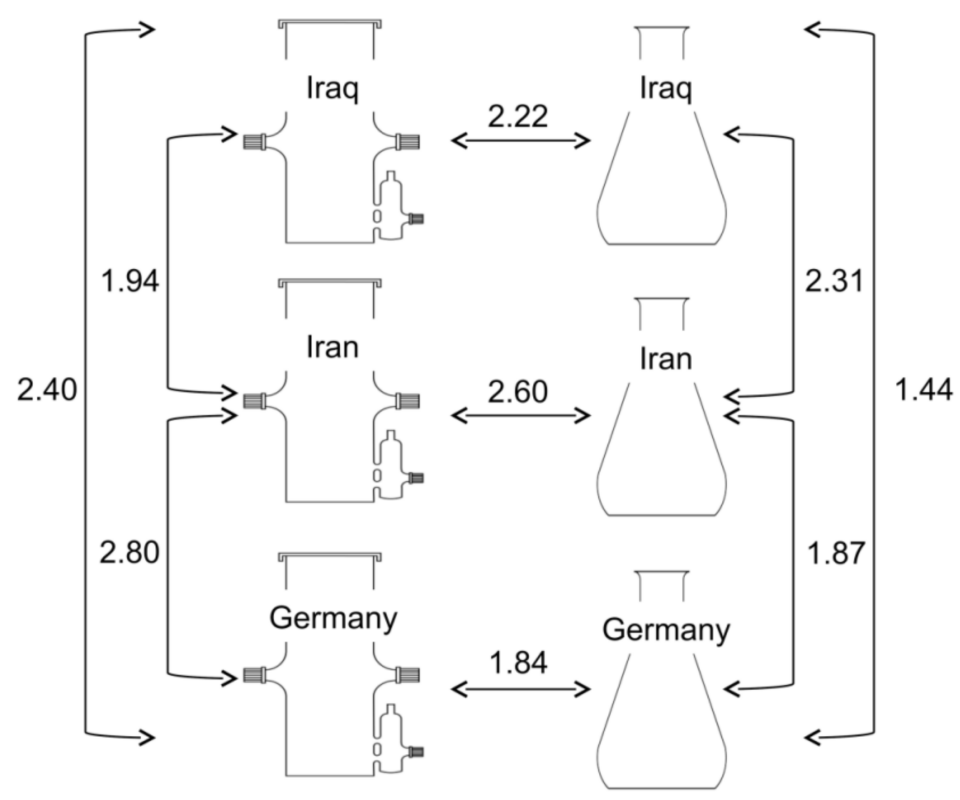

Figure 10. Euclidean distances between normalized metabolic profiles of hairy root exudates obtained from three accessions of Hyoscyamus niger (designated Iraq, Iran and Germany) grown in bioreactors and flask cultures.

\section{Conclusions}

The bioreactor designed in this work proved suitable for growing plants in sterile hydroponics, for cultivating hairy roots, and for collecting root and hairy root exudates. Hairy root cultures accumulated biomass at a comparable rate or faster in the bioreactor than in shaking flasks. The bioreactor outperformed shaking flasks regarding the diversity and quantity of hairy root exudates of $H$. niger.

Validation experiments lead to new findings regarding the metabolic diversity in hairy root exudates of Hyoscyamus niger, which turned out to be incongruent with the genetic relationships among 
plant accessions. Salicylic acid secretion by hairy roots of Hyoscyamus niger varied widely among plant accessions and between cultivation conditions.

Author Contributions: Conceptualization, A.H.A.H.R. and P.K.; Formal analysis, F.H. and P.K.; Funding acquisition, A.H.A.H.R. and P.K.; Investigation, Z.J.K., L.S., A.R., A.S., and F.H.; Methodology, Z.J.K., L.S., A.R., A.S. and F.H.; Resources, A.H.A.H.R. and P.K.; Validation, Z.J.K., L.S. and A.R.; Visualization, Z.J.K., L.S., A.R., F.H., and P.K.; Writing_-original draft, P.K.; Writing—review and editing, P.K.

Funding: This research was funded by the University of Sulaimani, Iraqi Kurdistan Region, and by German Research Foundation (DFG IRTG 2172).

Acknowledgments: The authors are obliged to Hernan Laurentin for providing sesame seeds and Ruth Pilot for technical assistance.

Conflicts of Interest: The authors declare no conflict of interest. The funders had no role in the design of the study; in the collection, analyses, or interpretation of data; in the writing of the manuscript, or in the decision to publish the results.

\section{References}

1. Khorassini, R.; Hettwer, U.; Ratzinger, A.; Steingrobe, B.; Karlovsky, P.; Claassen, N. Citramalic acid and salicylic acid in sugar beet root exudates solubilize soil phosphorus. BMC Plant Biol. 2011, 11, 121. [CrossRef] [PubMed]

2. Tawaraya, K.; Horie, R.; Saito, S.; Wagatsuma, T.; Saito, K.; Oikawa, A. Metabolite profiling of root exudates of common bean under phosphorus deficiency. Metabolites 2014, 4, 599-611. [CrossRef] [PubMed]

3. Zhang, D.; Zhang, C.; Tang, X.; Li, H.; Zhang, F.; Rengel, Z.; Whalley, W.R.; Davies, W.J.; Shen, J. Increased soil phosphorus availability induced by faba bean root exudation stimulates root growth and phosphorus uptake in neighbouring maize. New Phytol. 2016, 209, 823-831. [CrossRef] [PubMed]

4. Hu, L.; Robert, C.A.M.; Cadot, S.; Zhang, X.; Ye, M.; Li, B.; Manzo, D.; Chervet, N.; Steinger, T.; van der Heijden, M.G.A.; et al. Root exudate metabolites drive plant-soil feedbacks on growth and defense by shaping the rhizosphere microbiota. Nature Commun. 2018, 9, 2738. [CrossRef] [PubMed]

5. Watt, M.; Kirkegaard, J.A.; Passioura, J.B. Rhizosphere biology and crop productivity—a review. Soil Res. 2006, 44, 299-317. [CrossRef]

6. Miller, S.B.; Heuberger, A.L.; Broeckling, C.D.; Jahn, C.E. Non-targeted metabolomics reveals sorghum rhizosphere-associated exudates are influenced by the belowground interaction of substrate and sorghum genotype. Int. J. Mol. Sci. 2019, 20, 431. [CrossRef] [PubMed]

7. Huber, M.; Bont, Z.; Fricke, J.; Brillatz, T.; Aziz, Z.; Gershenzon, J.; Erb, M. A below-ground herbivore shapes root defensive chemistry in natural plant populations. Proc. Biol. Sci. 2016, 283, 20160285. [CrossRef] [PubMed]

8. Steinkellner, S.; Lendzemo, V.; Langer, I.; Schweiger, P.; Khaosaad, T.; Toussaint, J.P.; Vierheilig, H. Flavonoids and strigolactones in root exudates as signals in symbiotic and pathogenic plant-fungus interactions. Molecules 2007, 12, 1290-1306. [CrossRef]

9. Lanoue, A.; Burlat, V.; Schurr, U.; Röse, U.S.R. Induced root-secreted phenolic compounds as a belowground plant defense. Plant Signal. Behav. 2010, 5, 1037-1038. [CrossRef]

10. Arafat, Y.; Wei, X.; Jiang, Y.; Chen, T.; Saqib, H.S.A.; Lin, S.; Lin, W. Spatial distribution patterns of root-associated bacterial communities mediated by root exudates in different aged ratooning tea monoculture systems. Int. J. Mol. Sci. 2017, 18, 1727. [CrossRef]

11. Hiltpold, I.; Jaffuel, G.; Turlings, T.C.J. The dual effects of root-cap exudates on nematodes: From quiescence in plant-parasitic nematodes to frenzy in entomopathogenic nematodes. J. Exp. Bot. 2015, 66, 603-611. [CrossRef] [PubMed]

12. Georgiev, M.I.; Agostini, E.; Ludwig-Müller, J.; Xu, J. Genetically transformed roots: From plant disease to biotechnological resource. Trends Biotechnol. 2012, 30, 528-537. [CrossRef] [PubMed]

13. Bulgakov, V.P.; Shkryl, Y.N.; Veremeichik, G.N.; Gorpenchenko, T.Y.; Vereshchagina, Y.V. Recent advances in the understanding of Agrobacterium rhizogenes-derived genes and their effects on stress resistance and plant metabolism. Adv. Biochem. Eng. Biotechnol. 2013, 134, 1-22. [CrossRef] [PubMed] 
14. Yu, H.; Guo, W.; Yang, D.; Hou, Z.; Liang, Z. Transcriptional profiles of SmWRKY family genes and their putative roles in the biosynthesis of tanshinone and phenolic acids in Salvia miltiorrhiza. Int. J. Mol. Sci. 2018, 19, 1593. [CrossRef] [PubMed]

15. Shi, W.Y.; Du, Y.T.; Ma, J.; Min, D.H.; Jin, L.G.; Chen, J.; Chen, M.; Zhou, Y.B.; Ma, Y.Z.; Xu, Z.S.; et al. The WRKY transcription factor GmWRKY12 confers drought and salt tolerance in soybean. Int. J. Mol. Sci. 2018, 19. [CrossRef] [PubMed]

16. Sańko-Sawczenko, I.; Dmitruk, D.; Łotocka, B.; Różańska, E.; Czarnocka, W. Expression analysis of pin genes in root tips and nodules of Lotus japonicus. Int. J. Mol. Sci. 2019, 20, 235. [CrossRef] [PubMed]

17. Bai, Z.; Xia, P.; Wang, R.; Jiao, J.; Ru, M.; Liu, J.; Liang, Z. Molecular cloning and characterization of five SmGRAS genes associated with tanshinone biosynthesis in Salvia miltiorrhiza hairy roots. PLoS ONE 2017, 12, e0185322. [CrossRef] [PubMed]

18. Morriss, S.C.; Studham, M.E.; Tylka, G.L.; MacIntosh, G.C. Validation of a hairy roots system to study soybean-soybean aphid interactions. PLoS ONE 2017, 12, e0174914. [CrossRef]

19. Georgiev, M.I.; Pavlov, A.I.; Bley, T. Hairy root type plant in vitro systems as sources of bioactive substances. Appl. Microbiol. Biotechnol. 2007, 74, 1175-1185. [CrossRef]

20. Kochan, E.; Balcerczak, E.; Szymczyk, P.; Sienkiewicz, M.; Zielińska-Bliźniewska, H.; Szymańska, G. Abscisic acid regulates the 3-hydroxy-3-methylglutaryl CoA reductase gene promoter and ginsenoside production in Panax quinquefolium hairy root cultures. Int. J. Mol. Sci. 2019, 20, 1310. [CrossRef]

21. Renouard, S.; Corbin, C.; Drouet, S.; Medvedec, B.; Doussot, J.; Colas, C.; Maunit, B.; Bhambra, A.S.; Gontier, E.; Jullian, N.; et al. Investigation of Linum flavum (L.) hairy root cultures for the production of anticancer aryltetralin lignans. Int. J. Mol. Sci. 2018, 19, 990. [CrossRef] [PubMed]

22. Srivastava, S.; Srivastava, A.K. Hairy root culture for mass-production of high-value secondary metabolites. Crit. Rev. Biotechnol. 2007, 27, 29-43. [CrossRef]

23. Nakajima, K.; Hashimoto, T. Two tropinone reductases, that catalyze opposite stereospecific reductions in tropane alkaloid biosynthesis, are localized in plant root with different cell-specific patterns. Plant Cell Physiol. 1999, 40, 1099-1107. [CrossRef]

24. Lee, Y.S.; Ku, K.M.; Becker, T.M.; Juvik, J.A. Chemopreventive glucosinolate accumulation in various broccoli and collard tissues: Microfluidic-based targeted transcriptomics for by-product valorization. PLoS ONE 2017, 12, e0185112. [CrossRef]

25. Jouhikainen, K.; Lindgren, L.; Jokelainen, T.; Hiltunen, R.; Teeri, T.H.; Oksman-Caldentey, K.M. Enhancement of scopolamine production in Hyoscyamus muticus L. hairy root cultures by genetic engineering. Planta 1999, 208, 545-551. [CrossRef]

26. Ludwig-Müller, J.; Jahn, L.; Lippert, A.; Püschel, J.; Walter, A. Improvement of hairy root cultures and plants by changing biosynthetic pathways leading to pharmaceutical metabolites: Strategies and applications. Biotechnol. Adv. 2014, 32, 1168-1179. [CrossRef]

27. Guo, Z.; Tan, H.; Lv, Z.; Ji, Q.; Huang, Y.; Liu, J.; Chen, D.; Diao, Y.; Si, J.; Zhang, L. Targeted expression of Vitreoscilla hemoglobin improves the production of tropane alkaloids in Hyoscyamus niger hairy roots. Sci. Rep. 2018, 8, 17969. [CrossRef]

28. Wei, T.; Gao, Y.; Deng, K.; Zhang, L.; Yang, M.; Liu, X.; Qi, C.; Wang, C.; Song, W.; Zhang, Y.; et al. Enhancement of tanshinone production in Salvia miltiorrhiza hairy root cultures by metabolic engineering. Plant Methods 2019, 15, 53. [CrossRef]

29. Kirchner, T.W.; Niehaus, M.; Debener, T.; Schenk, M.K.; Herde, M. Efficient generation of mutations mediated by CRISPR/Cas9 in the hairy root transformation system of Brassica carinata. PLoS ONE 2017, 12, e0185429. [CrossRef]

30. Madeira, L.M.; Szeto, T.H.; Henquet, M.; Raven, N.; Runions, J.; Huddleston, J.; Garrard, I.; Drake, P.M.W.; Ma, J.K.C. High-yield production of a human monoclonal IgG by rhizosecretion in hydroponic tobacco cultures. Plant Biotechnol. J. 2016, 14, 615-624. [CrossRef]

31. Mai, N.T.P.; Boitel-Conti, M.; Guerineau, F. Arabidopsis thaliana hairy roots for the production of heterologous proteins. Plant Cell Tissue Organ Cult. 2016, 127, 489-496. [CrossRef]

32. Häkkinen, S.T.; Raven, N.; Henquet, M.; Laukkanen, M.L.; Anderlei, T.; Pitkänen, J.P.; Twyman, R.M.; Bosch, D.; Oksman-Caldentey, K.M.; Schillberg, S.; et al. Molecular farming in tobacco hairy roots by triggering the secretion of a pharmaceutical antibody. Biotechnol. Bioeng. 2014, 111, 336-346. [CrossRef] 
33. Van Leeuwen, W.; Ruttink, T.; Borst-Vrenssen, A.W.; van der Plas, L.H.; van der Krol, A.R. Characterization of position-induced spatial and temporal regulation of transgene promoter activity in plants. J. Exp. Bot. 2001, 52, 949-959. [CrossRef]

34. Laurentin, H.; Ratzinger, A.; Karlovsky, P. Relationship between metabolic and genomic diversity in sesame (Sesamum indicum L.). BMC Genom. 2008, 9, 250. [CrossRef]

35. Sarrou, E.; Ganopoulos, I.; Xanthopoulou, A.; Masuero, D.; Martens, S.; Madesis, P.; Mavromatis, A.; Chatzopoulou, P. Genetic diversity and metabolic profile of Salvia officinalis populations: Implications for advanced breeding strategies. Planta 2017, 246, 201-215. [CrossRef] [PubMed]

36. Watanabe, S.; Ohtani, Y.; Aoki, W.; Uno, Y.; Sukekiyo, Y.; Kubokawa, S.; Ueda, M. Detection of betacyanin in red-tube spinach (Spinacia oleracea) and its biofortification by strategic hydroponics. PLoS ONE 2018, 13, e0203656. [CrossRef]

37. Kittipongpatana, N.; Hock, R.S.; Porter, J.R. Production of solasodine by hairy root, callus, and cell suspension cultures of Solanum aviculare Forst. Plant Cell Tissue Organ Cult. 1998, 52, 133-143. [CrossRef]

38. Palavalli, R.R.; Srivastava, S.; Srivastava, A.K. Development of a mathematical model for growth and oxygen transfer in in vitro plant hairy root cultivations. Appl. Biochem. Biotechnol. 2012, 167, 1831-1844. [CrossRef]

39. Georgiev, M.I.; Eibl, R.; Zhong, J.J. Hosting the plant cells in vitro: Recent trends in bioreactors. Appl. Microbiol. Biotechnol. 2013, 97, 3787-3800. [CrossRef]

40. Homova, V.; Weber, J.; Schulze, J.; Alipieva, K.; Bley, T.; Georgiev, M. Devil's claw hairy root culture in flasks and in a 3-L bioreactor: Bioactive metabolite accumulation and flow cytometry. Z. Nat. C J. Biosci. 2010, 65, 472-478. [CrossRef]

41. Patra, N.; Srivastava, A.K. Enhanced production of artemisinin by hairy root cultivation of Artemisia annua in a modified stirred tank reactor. Appl. Biochem. Biotechnol. 2014, 174, 2209-2222. [CrossRef]

42. Medina-Bolívar, F.; Cramer, C. Production of recombinant proteins by hairy roots cultured in plastic sleeve bioreactors. Methods Mol. Biol. 2004, 267, 351-363. [CrossRef]

43. Kwok, K.H.; Doran, P.M. Kinetic and stoichiometric analysis of hairy roots in a segmented bubble column reactor. Biotechnol. Prog. 1995, 11, 429-435. [CrossRef]

44. Weathers, P.J.; Giles, K.L. Regeneration of plants using nutrient mist culture. Vitr. Cell. Dev. Biol. 1988, 24, 727-732. [CrossRef]

45. Tscheschke, B.; Dreimann, J.; von der Ruhr, J.W.; Schmidt, T.; Stahl, F.; Just, L.; Scheper, T. Evaluation of a new mist-chamber bioreactor for biotechnological applications. Biotechnol. Bioeng. 2015, 112, 1155-1164. [CrossRef]

46. Caspeta, L.; Quintero, R.; Villarreal, M.L. Novel airlift reactor fitting for hairy root cultures: Developmental and performance studies. Biotechnol. Prog. 2005, 21, 735-740. [CrossRef]

47. Williams, G.R.; Doran, P.M. Hairy root culture in a liquid-dispersed bioreactor: Characterization of spatial heterogeneity. Biotechnol. Prog. 2000, 16, 391-401. [CrossRef]

48. Higuchi, M.; Kunitomo, N.; Kobayashi, Y.; Kumada, K.; Tanaka, N. Bioreactor using oxygen-enriched micro/nano-bubbles. International Patent Application No. PCT/JP2015/071597, 2 February 2017.

49. Khuntia, S.; Majumder, S.K.; Ghosh, P. Microbubble-aided water and wastewater purification: A review. Rev. Chem. Eng. 2012, 28, 191-221. [CrossRef]

50. Al-Mashhadani, M.K.H.; Wilkinson, S.J.; Zimmerman, W.B. Airlift bioreactor for biological applications with microbubble mediated transport processes. Chem. Eng. Sci. 2015, 137, 243-253. [CrossRef]

51. Mochida, K.; Furuta, T.; Ebana, K.; Shinozaki, K.; Kikuchi, J. Correlation exploration of metabolic and genomic diversity in rice. BMC Genom. 2009, 10, 568. [CrossRef]

52. Moore, B.D.; Andrew, R.L.; Külheim, C.; Foley, W.J. Explaining intraspecific diversity in plant secondary metabolites in an ecological context. New Phytol. 2014, 201, 733-750. [CrossRef]

53. Rengel, Z. Genetic control of root exudation. Plant Soil 2002, 245, 59-70. [CrossRef]

54. Klessig, D.F.; Malamy, J. The salicylic acid signal in plants. Plant Mol. Biol. 1994, 26, 1439-1458. [CrossRef]

55. Ratzinger, A.; Riediger, N.; von Tiedemann, A.; Karlovsky, P. Salicylic acid and salicylic acid glucoside in xylem sap of Brassica napus infected with Verticillium longisporum. J. Plant Res. 2009, 122, 571-579. [CrossRef]

56. Lebeis, S.L.; Paredes, S.H.; Lundberg, D.S.; Breakfield, N.; Gehring, J.; McDonald, M.; Malfatti, S.; Glavina del Rio, T.; Jones, C.D.; Tringe, S.G.; et al. Salicylic acid modulates colonization of the root microbiome by specific bacterial taxa. Science 2015, 349, 860-864. [CrossRef] 
57. Sirrenberg, A.; Nutz, S.; Ratzinger, A.; Karlovsky, P. Replant disease of roses-new research approaches. Gartenpraxis 2009, 9, 16-20.

58. Zedníková, M.; Orvalho, S.; Fialová, M.; Ruzicka, M.C. Measurement of volumetric mass transfer coefficient in bubble columns. ChemEngineering 2018, 2, 19. [CrossRef]

59. Vervliet, G.; Holsters, M.; Teuchy, H.; Van Montagu, M.; Schell, J. Characterization of different plaque-forming and defective temperate phages in Agrobacterium. J. Gen. Virol. 1975, 26, 33-48. [CrossRef]

60. Murashige, T.; Skoog, F. A revised medium for rapid growth and bioassays with tobacco tissue culture. Physiol. Plant. 1962, 15, 473-497. [CrossRef]

61. Kumar, S.; Stecher, G.; Li, M.; Knyaz, C.; Tamura, K. MEGA X: Molecular evolutionary genetics analysis across computing platforms. Mol. Biol. Evol. 2018, 35, 1547-1549. [CrossRef]

62. Hand, D.W. Effects of atmospheric humidity on greenhouse crops. Acta Hortic. 1988, 229, 143-158. [CrossRef]

63. Cámara-Zapata, J.M.; Sánchez-Molina, J.A.; Rodríguez, F.; López, J.C. Evaluation of a dehumidifier in a mild weather greenhouse. Appl. Therm. Eng. 2019, 146, 92-103. [CrossRef]

64. Ramirez-Estrada, K.; Vidal-Limon, H.; Hidalgo, D.; Moyano, E.; Golenioswki, M.; Cusidó, R.M.; Palazon, J. Elicitation, an effective strategy for the biotechnological production of bioactive high-added value compounds in plant cell factories. Molecules 2016, 21, 182. [CrossRef]

65. Kang, S.M.; Jung, H.Y.; Kang, Y.M.; Yun, D.J.; Bahk, J.D.; Yang, J.; Choi, M.S. Effects of methyl jasmonate and salicylic acid on the production of tropane alkaloids and the expression of PMT and $\mathrm{H} 6 \mathrm{H}$ in adventitious root cultures of Scopolia parviflora. Plant Sci. 2004, 166, 745-751. [CrossRef]

66. Harfi, B.; Khelifi, L.; Khelifi-Slaoui, M.; Assaf-Ducrocq, C.; Gontier, E. Tropane alkaloids GC/MS analysis and low dose elicitors' effects on hyoscyamine biosynthetic pathway in hairy roots of Algerian Datura species. Sci. Rep. 2018, 8, 17951. [CrossRef]

67. Adnani, N.; Michel, C.R.; Bugni, T.S. Universal quantification of structurally diverse natural products using an evaporative light scattering detector. J. Nat. Prod. 2012, 75, 802-806. [CrossRef]

68. Houshyani, B.; Kabouw, P.; Muth, D.; de Vos, R.C.H.; Bino, R.J.; Bouwmeester, H.J. Characterization of the natural variation in Arabidopsis thaliana metabolome by the analysis of metabolic distance. Metabolomics 2012, 8, 131-145. [CrossRef]

69. Lamine, M.; Rahali, F.Z.; Hamdaoui, G.; Selmi, S.; Mliki, A.; Gargouri, M. Associating chemical analysis to molecular markers for the valorization of Citrus aurantium leaves: A useful starting point for marker-assisted selection. Euphytica 2017, 213, 44. [CrossRef]

70. Grynkiewicz, G.; Gadzikowska, M. Tropane alkaloids as medicinally useful natural products and their synthetic derivatives as new drugs. Pharmacol. Rep. 2008, 60, 439-463.

71. Hashimoto, T.; Yukimune, Y.; Yamada, Y. Tropane alkaloid production in Hyoscyamus root cultures. J. Plant Physiol. 1986, 124, 61-75. [CrossRef] 